\title{
Cooperative Intuitionism
}

DOI:

10.1093/pq/pqaa011

\section{Document Version}

Accepted author manuscript

Link to publication record in Manchester Research Explorer

\section{Citation for published version (APA):}

Ingram, S. (2020). Cooperative Intuitionism. The Philosophical Quarterly. https://doi.org/10.1093/pq/pqaa011

\section{Published in:}

The Philosophical Quarterly

\section{Citing this paper}

Please note that where the full-text provided on Manchester Research Explorer is the Author Accepted Manuscript or Proof version this may differ from the final Published version. If citing, it is advised that you check and use the publisher's definitive version.

\section{General rights}

Copyright and moral rights for the publications made accessible in the Research Explorer are retained by the authors and/or other copyright owners and it is a condition of accessing publications that users recognise and abide by the legal requirements associated with these rights.

\section{Takedown policy}

If you believe that this document breaches copyright please refer to the University of Manchester's Takedown Procedures [http://man.ac.uk/04Y6Bo] or contact uml.scholarlycommunications@manchester.ac.uk providing relevant details, so we can investigate your claim.

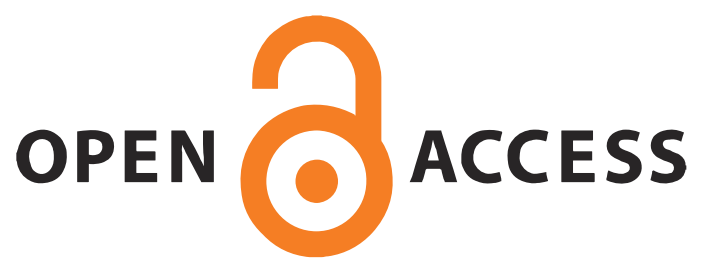


This is the penultimate version of an article that currently forthcoming in The Philosophical Quarterly. You can access the official version here.

\title{
Cooperative Intuitionism
}

\begin{abstract}
According to pluralistic intuitionist theories, some of our moral beliefs are non-inferentially justified, and these beliefs come in both an a priori and an a posteriori variety. In this paper I present new support for this pluralistic form of intuitionism by examining the deeply social nature of moral inquiry. This is something that intuitionists have tended to neglect. It does play an important role in an intuitionist theory offered by Bengson, Cuneo, and Shafer-Landau (forth), but whilst they invoke the social nature of moral inquiry in order to argue that ordinary moral intuitions are trustworthy, my argument focuses on what I will call the 'frontiers' of moral inquiry. I will show that inclusive and cooperative dialogue is necessary at moral inquiry's frontiers, and that intuitionists can expect such dialogue to result in both a priori and a posteriori moral beliefs.
\end{abstract}

\section{Keywords}

Moral intuitionism; moral epistemology; feminist epistemology; moral experience; moral dialogue. 
Moral intuitionism is the view that some moral beliefs are non-inferentially justified or warranted. ${ }^{1}$ Intuitionists have often been rationalists - that is, they have often argued that moral knowledge is fundamentally a priori. However, in recent years some philosophers have offered empiricist forms of intuitionism. ${ }^{2}$ On such views we have distinctively moral experiences that supply non-inferential but a posteriori justification for moral belief. This paper offers a pluralistic form of intuitionism, one on which a priori and a posteriori intuition are both central to moral inquiry. I develop this approach by exploring the social character of moral inquiry - specifically, the role that moral dialogue plays in the formation of justified moral beliefs. I aim to show that, by attending to the dialogical aspects of moral inquiry, we see that both a priori and a posteriori justification must be central to intuitionist epistemology.

The social nature of moral inquiry has mostly been neglected by intuitionists. It does figure in a recent intuitionist theory offered by Bengson, Cuneo, and Shafer-Landau (forth), but whereas they invoke the social nature of moral inquiry to argue that ordinary moral thought is trustworthy, my focus will be on what I'll call the 'frontiers' of moral inquiry - areas of inquiry in which we go beyond ordinary thought, beyond the established facts, and beyond the simple application of such facts in new contexts. I argue that, at inquiry's frontiers, inclusive and cooperative moral dialogue is not just useful but necessary (\$1). I then show that we can expect such dialogue to generate some moral beliefs that are justified a priori $(\$ 2)$ and some that are justified by a posteriori moral experience (\$3).

\footnotetext{
${ }^{1}$ Intuitionism has a long history, but its recent supporters include Shafer-Landau (2003), Audi (2004), Huemer (2005), Tropman (2009), Kaspar (2012), and Stratton-Lake (2016).

${ }^{2}$ For discussion of empiricist forms of intuitionism, see e.g. Oddie (2005), McBrayer (2010), Audi (2013), and Cowan (2016). As I note in \3, empiricist intuitionism can but need not involve claims about moral perception.
} 


\section{$1 \quad$ Moral Dialogue}

This section argues that inclusive and cooperative dialogue is essential for the justification of some moral beliefs. Specifically, beliefs formed at the 'frontiers' of moral inquiry are not justified unless they result from, or have been tested against, appropriate moral dialogue. Many of the points made here apply to any moral epistemology - in later sections I explain what intuitionists can learn from them.

\subsection{Objective Inquiry}

Inquiry is often a collaborative activity, involving ongoing discourse between the members of an epistemic community. Even as an inquirer works alone to find something out, in many cases she will be building (perhaps unconsciously) on the insights and errors of earlier inquirers, and she will be relying on concepts, beliefs, and methods that have been taught or transmitted by her epistemic community. More generally, we often make discoveries and identify justified beliefs by pooling our epistemic resources. We rely on testimony, we form or refine beliefs via discussion and debate, we leave some questions for others to answer, and so on. These facts about intellectual life are in some ways banal, but until relatively recently they were neglected in mainstream analytic epistemological thought.

Moreover, the fact that inquiry is shaped by social dynamics has implications for how it is conducted. For instance, a major theme of feminist epistemology is that inquiry's social nature has implications for how we understand and engage in 'objective' inquiry. Feminist authors (including e.g. Longino 1990, Harding 1991, Antony 1993, and Anderson 1995) argue that ideals of objectivity have traditionally been tied to a notion of neutrality. On this traditional approach, objective inquiry demands that one set aside one's desires, emotions, values, and interests - such factors are held to involve subjective partialities and biases that distort judgement. Thus, the objective inquirer must enter a standpoint at which they are strictly impartial - a detached standpoint that transcends their own. 
The idea here is that, by aiming for neutrality of this sort, one puts oneself in a position to see reality as it truly is, unburdened by thoughts of how one wants, imagines, or assumes it to be. ${ }^{3}$ Most feminist epistemologists, however, are critical of the idea that we should inquire in a neutral, impartial, or detached manner. One worry about this approach is that what we traditionally regard as a neutral standpoint is actually itself saturated by various biases, values, partialities, and interests (cf. Antony 1993). These manifest by determining the questions that we think to ask, the answers that we can imagine those questions having, and even our views on a given answer's plausibility. For a possible answer to some question may seem less plausible to you if it does not match your experiences of the world, and your experiences are shaped by your particular social and historical position.

If the allegedly neutral standpoint seems cognitively 'pure', this is because its biases are so entrenched that they are now 'invisible background assumptions' of inquiry (cf. Longino 1990: 80). Moreover, the biases that typically prevail in mainstream inquiry are those of the powerful, at the expense of those of the marginalised and oppressed. There is thus only so much that a competent and conscientious an inquirer can do on their own, for they occupy a social and historical position that limits the borders of their inquiry. Far from giving a fuller and more accurate picture of the world - one guided by how it really is - the traditional conception of objectivity is thus distortingly partial.

\footnotetext{
${ }^{3}$ This 'traditional' view of objectivity is somewhat caricatured, but influential philosophers offer views like it for some domains - see e.g. Sidgwick (1907) on 'the point of view of the universe,' Williams (1978) on the 'absolute conception' of the universe, and Nagel (1986) on the 'view from nowhere.' Moreover, ideals of neutrality plausibly influence much of pre-reflective thought about objectivity. It's worth noting this traditional view of objectivity has also been criticised from beyond the feminist tradition, e.g. by Wiggins (1987) and McDowell (1998: 126-129), among others.
} 
This doesn't mean that we must give up on objective inquiry. Feminist philosophers have developed more promising interpretations of objectivity. ${ }^{4}$ For instance, Longino says the following about scientific practice:

The greater the number of different points of view included in a given community, the more likely it is that its scientific practice will be objective, that is, that it will result in descriptions and explanations of natural processes that are more reliable in the sense of less characterized by idiosyncratic subjective preferences of community members than would otherwise be the case (1990: 80).

The general (and very plausible) idea here is that inquiry is more objective when it is more inclusive. Objectivity doesn't require neutrality, but an inclusive and cooperative engagement with all salient voices.

Feminist moral epistemology has a similarly social focus. For instance, Jaggar observes that feminists typically operate with an epistemology in which dialogue is central:

Feminists have typically begun from the empirical recognition that the insights of moral agents are always conditioned by their particular social experiences and locations. Because all agents are limited and fallible, feminists generally conceptualize moral rationality as a process that is collaborative rather than individual ... Many of the alternative models of moral rationality proffered by feminists assert the necessity of empirical conversation (2000: 463).

There are various ways of fleshing this out, but what unites most feminist moral epistemologies is the plausible idea that moral inquiry is more objective when it involves inclusive and cooperative dialogue..$^{5}$ say more about how such dialogue works below. I first want to explain its role in moral inquiry.

\footnotetext{
${ }^{4}$ See e.g. Keller (1985), Longino (1990), Harding (1993), and Solomon (2001).

${ }^{5}$ For different ways of developing this point, see e.g. Walker (2007), O’Connor (2008), and Jaggar and Tobin (2013).
} 


\subsection{Dialogue's Role}

There are some basic moral truths that can be known with minimal cognitive effort. This is a point on which many moral epistemologists would agree, intuitionists included. For instance, Sidgwick (1907: 101-102) saw philosophical intuitionism as a way of tidying up and synthesising the moral principles that we already know through common sense, and Ross (1930: 39-41) explicitly appeals to 'what we really think' about moral questions. (Ross also argues that moral convictions must be subjected to reflection and critical comparison, but he does operate on the assumption that at least some moral beliefs (e.g. in the promissory principle) are common knowledge (Ross 1930: 20n.1)). More recently, Kaspar has argued that 'we know what's right, and thus have no need to deduce, derive, or justify our moral knowledge by means of a supreme moral principle' (2012: 4). Kaspar recognises that difficulties arise when we seek to apply knowledge of general (albeit non-supreme) moral principles to particular situations, but his thought is that many of the basic moral facts can be known with little cognitive effort. They certainly don't require inclusive and cooperative moral dialogue.

I find these claims plausible. There is room to refine our basic moral thoughts, and perhaps (contra Kaspar) to unify them with a 'supreme' principle, but it is hard to see how we can conduct moral inquiry unless we can assume knowledge of certain moral facts as a starting point - including, for instance, that it is pro tanto wrong to lie, kill, and break promises. These are examples of general moral facts that I know without engaging in inclusive and cooperative dialogue. What, then, is the role of such dialogue supposed to be? Note first that, although I needn't engage in actual dialogue with others to learn many of the basic moral facts, I do not come to them alone either - as Ross suggests, our existing moral knowledge 'is the cumulative product of the moral reflection of many generations' (1930: 41). In a sense, then, our existing moral knowledge is the result of an ongoing intergenerational dialogue in which everyone plays a part (cf. Bengson, Cuneo, and Shafer-Landau forth). 
More interesting, however, is dialogue's role at the frontiers of moral inquiry. Even if we already know that it is pro tanto wrong to lie and kill, the questions that remain open in moral inquiry do not just concern how such principles are applied. For intuitionists, they include questions about what we can add to a list of basic moral facts. Ross offered prima facie duties of fidelity, reparation, gratitude, justice, beneficence, self-improvement, and non-maleficence, but he didn't take this list to be complete, and later intuitionists have added to it (see e.g. Audi 2004: 194-195). There are also questions about the possibility of unifying moral principles. Some intuitionists (e.g. Kaspar 2012) hold that no 'supreme' principle is needed, but others defend such principles (see e.g. Moore 1903, Sidgwick 1907, and Audi 2004). In short, whilst there are important moral facts that we know with minimal effort, there are also deep and as yet unresolved moral questions at the frontiers of moral inquiry.

This is one reason dialogue is needed. Consider that it is possible - I think likely - that the marginalisation of certain social groups has led to some candidates for intuitable moral truth being neglected. The following is such a candidate:

CARE. Our caring relationships with others have basic moral significance, such that we have direct pro tanto reason to sustain those caring relationships, and to prioritise the needs of those with whom we have such relationships.

Philosophers have only recently begun to attend to principles like CARE. It has been argued, I think plausibly, that this is partly because philosophy has long been a male-dominated field, whilst care is a culturally feminine value (cf. Jagger 2001). The thought is that failure to include women in the moral conversation meant that some important moral values or principles were not given their due - not until women entered the conversation, or at least became better placed to pursue their own conversations. In short, although CARE is (at least) a strong candidate for being an intuitable moral truth, we have only been in a position to view it as such since our moral dialogue has become more inclusive. 
I don't wish to suggest that it's just philosophers who have only recently begun to recognise the importance of care in ethical life. A major theme in discussions of care is that we are culturally conditioned to deliberate in ways that demote it as a moral and political value - theories of moral reasoning have historically been dominated by ideas of autonomy, rights, natural law, universality, impartiality, and so on (see e.g. Gilligan 1982 and Walker 2007). This isn't to say that care plays no role in ordinary moral thought, just that it has rarely been valorised as an ideal. To the extent that this is changing, it is due in no small part to the amplification of feminist voices in public discourse. The notion of care has also been neglected in public policymaking, for instance in how we view social issues like childcare (see e.g. Ruddick 1989), disability (see e.g. Kittay 1999), homelessness (see e.g. Noddings 2002), and the extension of the free market (see e.g. Held 2006). We can argue about how much significance care should have in ordinary moral thought and public policymaking, but the key point is that care has been neglected not just by philosophers, but also by mainstream moral and political thought. It is only recently that care and related values have been given their due in public discourse, and the efforts of feminist thinkers and activists have been central to this process.

Putting this more generally, one reason to introduce a key role for moral dialogue is that a diverse community of inquirers is more likely to include members whose social position puts them in a position to spot candidate moral truths that would otherwise be missed. But a more important reason is that, even once a proposition like CARE is noticed as a serious candidate for moral truth, those with certain social experiences may be poorly placed to evaluate its intuitional credentials on their own. Just as an (imaginary) agent with no experience of suffering may (when inquiring alone) struggle to grasp the moral significance of suffering, an agent who does not have the roles of carer or cared-for as core aspects of their social world might struggle to assess the plausibility of CARE. Dialogue with those who do have such social experiences would help such an agent in evaluating CARE. 
Of course, almost everyone has some experience of caring roles (and almost everyone has some experience of suffering). But it's worth emphasising that fully-fledged caring activity involves more than just partiality towards someone, and more than just a sensitivity to their needs (though this is important). Prioritising someone else's needs in the sense at work in CARE also means taking practical steps to meet those needs - caring involves a form of labour as well as certain emotional attachments. And, in many contexts, caring labour is (or has traditionally been) performed by the members of less privileged social groups. ${ }^{6}$ (Think, for example, about who tends to play a bigger role in the labour of caring for children, the elderly, the disabled, etc.). Dialogue with the members of those social groups - or, in fact, anyone with relevant experience of caring work - will thus help those with less experience when it comes to evaluating the status of CARE. (More on this in $\$ 2-\$ 3$ ). However, I don't just wish to suggest that dialogue often helps in moral inquiry. I have a stronger claim in mind. My stronger claim is that, at the frontiers of moral inquiry, our moral beliefs cannot be justified unless they derive from, or have been tested against, inclusive and cooperative moral dialogue.

The case for this stronger claim involves some general ideas about good epistemic practice, along with specific features of moral inquiry. Consider that, in general, inquirers should approach inquiry in an open-minded and humble way. We should be sensitive to our fallibility, and to our cognitive strengths and weaknesses. We should test our beliefs against rival ideas in order to assess whether they stand up to scrutiny. This is especially crucial at the frontiers of an inquiry - that is, when inquirers go beyond learning established facts, and beyond the application of old knowledge in novel contexts. For it is at inquiry's frontiers that our epistemic position is least secure, so it is here that we must be at our most intellectually cautious. I thus think that, in general, a pre-requisite for the justification of 'frontier beliefs' is that they are acquired through open-minded and humble inquiry.

\footnotetext{
${ }^{6}$ For discussion of the labour involved in care, see e.g. Tronto and Fisher (1990), Bubeck (1995), and Held (2006).
} 
Crucially for my purposes, humility and open-mindedness are facilitated by inclusive and cooperative dialogue. Recognising your fallibility, you want to see what others believe, and you can achieve this through dialogue. Recognising the need to test your view against rival ideas, you ensure that this dialogue includes people whose experiences and beliefs differ to your own. Of course, in many cases it doesn't take actual dialogue to achieve open-minded and humble inquiry. Often one can achieve this by imagining or reading about rival ideas, before considering them on one's own. However, at the frontiers of an inquiry in which social experiences are crucial data, inclusive and cooperative dialogue is not just helpful but necessary. For one's social experiences, and one's ability to adequately imagine or simulate others' social experiences, will be shaped by one's social position. Thus, in some inquiries, humility and open-mindedness require actual dialogue with those whose social world is relevantly different to yours. This is the only way to guarantee that you have all the data against which you must test your beliefs. Presumably, moral inquiry is an area in which social experience is vital data. So, to form frontier moral beliefs in a way that is humble and open-minded enough for them to be justified, such beliefs must result from, or be tested against, inclusive moral dialogue.

The necessity of inclusive and cooperative dialogue (at moral inquiry's frontiers) applies to any account of moral knowledge. But intuitionists have special reason to take note of it. I'll argue that, by explaining what inclusive and cooperative moral dialogue actually involves, we can provide new support for a pluralistic account of non-inferential moral knowledge - that is, an account on which a priori and a posteriori justification are both central to intuitionist moral inquiry. My goal in $\$ 2$ is to show that intuitionists should take moral dialogue to generate some a priori moral beliefs. My goal in $\$ 3$ is to show that they should also take such dialogue to generate some a posteriori moral beliefs. 
This section argues that intuitionists should take inclusive and cooperative dialogue to lead to some a priori justified moral beliefs. I begin by briefly clarifying how it is possible for empirical dialogical experiences to feature in the acquisition of a priori justified moral beliefs. I then explain why moral intuitionists can expect such beliefs to be an important product of inclusive and cooperative moral dialogue.

\section{$2.1 \quad$ E-Dependence and J-Dependence}

The standard image of a priori inquiry involves it being conducted 'from the armchair'. This image is misleading, and not just because one need not literally be sat in an armchair to do a priori inquiry. It is misleading because it involves a falsely individualistic picture of how a priori knowledge works. Consider what should be a familiar distinction between two ways in which beliefs may depend on experience: a belief might be justified by experience, or it might merely be enabled by experience (cf. Burge 1993). To illustrate, whilst my belief that all bachelors are unmarried men is a priori, I clearly had to learn the meanings of 'bachelor' and 'unmarried man' before I could form this belief. My belief that all bachelors are unmarried men therefore depends in a certain sense on my empirical learning experiences. But this doesn't make it a posteriori, for these experiences do not, or need not, play any role in the justification of my belief. They are part of its causal history, but this belief's epistemic justification need not involve its causal history. For I can be justified in believing that all bachelors are unmarried men simply by grasping the concepts 'bachelor' and 'unmarried man', and the relation between them. It plausibly takes empirical experience to become competent with these concepts, but once the relevant conceptual competence has been achieved I require no additional experience in order to be able to justifiably believe that all bachelors are unmarried men. My belief is therefore a priori even though there is a perfectly legitimate sense in which it is dependent upon experience. 
The important idea here is that a belief can be a priori even though empirical experience is essential to its causal history - as Burge (1993) puts it in another context, empirical experience may play an enabling role in the acquisition of an a priori belief, but what matters for that beliefs being a priori is its being non-experientially justified or warranted. ${ }^{7}$ In short, there is a distinction between 'justificatory dependence' and 'enabling dependence', which I'll hereafter refer to as 'J-dependence' and 'E-dependence'. It is a general epistemic fact that, even if a belief E-depends on experience, it is a prioriso long as it doesn't J-depend on experience. This point is built into even rationalist forms of intuitionism, which allow that a priori moral knowledge can E-depend on empirical experience. ${ }^{8}$ There is no limit to the kinds of experience on which an a priori belief may E-depend, so long as it doesn't J-depend on them. Our a priori beliefs can thus E-depend on social experiences, including those involved in moral dialogue. It is in some ways surprising that this is not part of our standard image of the a priori, for the most famous early example of a priori reasoning involves dialogue. I'm thinking here of the conversation between Socrates and Meno's slave. What happens in the Meno is that, by asking the right questions, Socrates enables Meno's slave to form a priori beliefs about geometrical facts. ${ }^{9}$ This process puts the slave in a position to cognise geometrical ideas such that he grasps their truth. Without a dialogical interaction, and the experiences involved in it, this would not have happened. His beliefs thus E-depend on dialogical experiences, but needn't J-depend on them.

\footnotetext{
${ }^{7}$ Burge (1993) distinguishes justification and entitlement, which he respectively sees as internalist and externalist forms of warrant. I speak in terms of justification, simply because this is an easier way to articulate the points made below.

${ }^{8}$ Kirchin (2005) helpfully clarifies the enabling role played by empirical experience, but the point was also known to Ross (1930: 32-33) and other early intuitionists.

${ }^{9}$ Plato's theory of the a priori involves untenable claims about immortal souls, past lives, and hidden knowledge. This doesn't matter here.
} 
The slave's geometrical beliefs are instances of what we might call 'the cooperative a priori' Of course, Socrates' dialogue with the slave is not an ideal model for collaborative discourse - he asks leading questions, and his superior social status means that he and the slave cannot converse on equal terms. I examine how a better model for inclusive and cooperative moral dialogue might work in the rest of this paper, starting with its role in our coming to rationally intuit general moral norms.

\subsection{Neglected Principles}

I have already alluded to the role that I see for a priori intuition in moral dialogue. I claimed in $\$ 1.2$ that some candidate moral principles have been neglected by philosophical and mainstream moral thought. This is in part due to the marginalisation of social groups whose members are best placed to notice, articulate, and defend those principles. I gave CARE as an example, but there will be other candidates. They may include 'supreme' principles that aim to unify all the Rossian prima facie duties. But they will at least include defeasible principles with the modest generality found in those Rossian duties.

Either way, I suggest that a key part of the dialogical process through which these neglected principles are discovered, assessed, and justifiably believed or rejected is most plausibly viewed in rationalist terms. According to rationalist forms of intuitionism, a moral belief is non-inferentially justified if it is based on 'adequate understanding' of a self-evident proposition (cf. Audi 2004). My claim is that, when dialogue puts us in a position to justifiably believe a neglected moral principle, it often does so by enabling an adequate understanding of that principle. To support this, I'll show that, when we explain how inclusive and cooperative dialogue actually functions at the frontiers of moral inquiry, we find that it enables core elements of adequate moral understanding. I will outline what these core elements of adequate moral understanding are, in order to show that one must engage in inclusive and cooperative dialogue in order to adequately understand a neglected moral principle. 
Audi (2019) identifies nine conditions that must be met if one is to adequately understand a self-evident proposition. Inquirers can meet these more-or-less well, and can thus attain a better or worse understanding of the proposition in question. But, according to Audi (2019: 372), for an inquirer to have a minimally adequate understanding of that proposition - that is, an understanding of the sort that could supply justification for belief - each of the nine elements must be minimally satisfied. I won't argue that inclusive and cooperative dialogue is needed to enable all nine of Audi's aspects of adequate understanding, but I will argue that it is needed to enable the most important three. $^{10}$

First consider the element that Audi (2019: 364) calls 'recognitional range'. This is the range of cases that someone who understands a proposition must recognise as instantiating or illustrating it. For instance, those who understand that there is a pro tanto duty to keep promises must recognise that, having assured my colleague that I will meet her at 3pm, I have a pro tanto duty to meet her at $3 \mathrm{pm}$. Those who do not see this do not understand the proposition in question. This leads us to a second element of adequate understanding, which Audi (2019: 365) calls 'the sense of rejectability'. In addition to recognising when a case instantiates a proposition, adequate understanding requires the ability to recognise when a case fails to instantiate it. For instance, if I was coerced into telling my colleague that I would meet her at $3 \mathrm{pm}$, this case only appears to instantiate the proposition in question. Recognising that a coerced promise lacks moral force is plausibly part of understanding the promissory principle. In addition, the sense of rejectability involves seeing when a proposition looks similar to a self-evident truth but is not, in fact, equivalent to it. For instance, if you recognise that there is a pro tanto duty to keep promises, you must not believe that it is always wrong to break promises.

\footnotetext{
${ }^{10}$ The elements that I set aside are logical comprehension, explicative capacity, confirmational sensitivity, translational capacity, readiness to meet objections, and accessibility to occurrent thought. Dialogue may help with achieving these, but (for reasons I don't have space to explore) it isn't necessary for them.
} 
A third important element of adequate propositional understanding leads on from the first two. Audi (2019: 367-368) calls it 'discriminative acuity'. This involves not only the capacity to reject near-equivalents of a self-evident principle, but also some insight into the morally relevant differences between them (and, thus, cases that instantiate them). Audi illustrates this with a pair of superficially similar propositions: (a) that altruistic people tend to do good deeds towards others; and (b) that non-altruistic people tend to do bad deeds towards others. Audi sees (a) as self-evident (on a natural reading of 'tendency'). But he sees (b) as false, for a non-altruistic person might tend to do good deeds for others on a self-interested (and thus non-altruistic) basis. To fully understand (a) one must see this by virtue of being able to discriminate altruistic deeds from merely beneficent ones. That is, one's sense of rejectability must be informed by a sensitivity to a rather subtle moral distinction.

There is more to adequate understanding than recognitional range, a sense of rejectability, and discriminative acuity. But these are particularly important aspects of such understanding. My claim will be that, when we consider how moral dialogue works at the frontiers of moral inquiry, it seems to function as an enabler for these key elements of adequate understanding. For most of us, inclusive and cooperative moral dialogue isn't necessary for an adequate understanding of the promissory principle, or Audi's claim about altruism. But for reasons outlined in $\$ 1.2$, dialogue is crucial with neglected principles like CARE. To see this, suppose that you have little experience of caring roles. Suppose as well that such roles are most associated with social groups to which you do not belong. Given the epistemic limitations that this implies, you are not well-placed to evaluate CARE on your own. And, given that social experience will be crucial data in the evaluation of CARE, you recognise that open-minded and humble inquiry into this proposition requires that you engage in inclusive and cooperative dialogue with those who have relevant social experiences. The crucial question is this: what do you learn from such dialogue? How does it contribute to the appraisal of CARE? 
Plausibly, dialogue serves to test and improve your understanding of CARE, and it does so by testing and improving your recognitional range, sense of rejectability, and discriminative acuity. By listening openly to real experiences of care, inquirers with limited experience of caring roles can test and improve their grasp of which cases do and do not instantiate CARE. To see this, consider that there is a morally interesting distinction between (I) those who prioritise an elderly relative's needs because they judge that one must respect one's elders, and (II) those who prioritise an elderly relative's needs out of a caring concern for them. The moral difference between (I) and (II) lies in the fact that care involves a personal tie to a particular individual. It involves emotional connection, and a shared history. This distinguishes the moral import of caring relations from that of a general duty of respect for elders. (Such respect might be admirable, but it is morally distinct from caring). Note, however, that the activities involved in prioritising an elderly relative's needs are often the same in cases that instantiate (I) and (II). For instance, both will involve regular contact with them, listening to their advice, helping to look after them if they are unable to look after themselves, and so on.

Given the potential similarities between cases of (I) and (II), being able to recognise which actual cases instantiate (I) and which instantiate (II) will require a nuanced sensitivity to the salient features of specific cases. Those with limited experience of caring roles might lack this sensitivity. And, even if they do in fact possess the relevant sensitivity, for reasons outlined in $\$ 1.2$ they must at least regard themselves as especially fallible here. Thus, an inexperienced but open-minded and humble moral inquirer will seek to engage in cooperative dialogue with those who have the relevant experience of caring roles. Their dialogue will involve the inexperienced agent receptively listening to, asking about, and empathically engaging with actual caring encounters described by their more experienced interlocutor. It will involve (in a sense I develop in \3) attempting to view things from their point of view. My suggestion is that, in doing this, dialogue seems to be functioning as a way of testing and improving the less experienced moral inquirer's understanding of the neglected CARE principle. 
For consider that, by engaging with those who have more experience of caring roles, the inexperienced inquirer can learn to identify social nuances that distinguish cases like (I) from cases like (II). That is, by listening to descriptions of real examples of caring conduct and motivation, in all their complexity and detail, inquirers can test and improve their recognition of which cases do and do not instantiate CARE - they can test and improve their recognitional range and sense of rejectability with respect to a neglected principle. ${ }^{11}$ The same applies to their discriminative acuity, for sensitivity to the social nuances that distinguish care from respect (or benevolence, or altruism, etc.) will bring with it an insight into the moral differences between CARE and norms that provide similar guidance. In short, at moral inquiry's frontiers dialogue functions to test and improve one's recognitional range, sense of rejectability, and discriminative acuity with respect to neglected moral norms. ${ }^{12}$ Intuitionists should therefore expect inclusive and cooperative moral dialogue to produce at least some a priori moral beliefs. These beliefs E-depend on the experiences involved in empirical dialogue, but they don't J-depend on those experiences. For their justification remains a matter of our adequately understanding moral propositions. In the next section I will argue that intuitionists should also expect cooperative dialogue to generate moral beliefs with an a posteriori justification. The case for this depends in part on a more detailed description of how cooperative moral dialogue works.

\footnotetext{
${ }^{11}$ Note that, whilst testimony plays a role here, this isn't a case of an inquirer forming a moral belief on the basis of moral testimony. Whether moral testimony is epistemically kosher is debated (Wiland 2017 provides a pertinent defence of it), but what I'm suggesting needn't involve moral testimony. My claim is that to understand CARE one may need non-moral testimony about subtleties indicative of conduct based on care rather than respect alone (e.g. a carer's level of attentiveness to their elderly relative, the tone of voice they use in speaking to them, and other such indicators of caring attachment that go beyond the abstract belief that certain acts are owed to the cared-for as a matter of respect).

${ }^{12}$ I've focused on a dialogue between an inexperienced inquirer and an experienced inquirer. Not all dialogues are like this - most of us have varying levels of relevant experience, and this will shape how a given dialogue unfolds.
} 
I hinted in $\$ 2.2$ that inclusive and cooperative dialogue requires empathic engagement with others. I begin this section by clarifying what this involves. I then argue that, by examining the empathic dialogical process, we learn that intuitionists can defend a role for a posteriori intuition. My claim is not that empathic experiences are themselves the a posteriori justifiers for moral belief. My claim is rather that empathic dialogue can induce shifts in one's moral-emotional framework, and that such shifts function to reframe our moral experience of situations with which we are confronted. (This may involve a kind of moral perception, but I am neutral on this point. What matters is not whether moral experience is analogous to ordinary perceptual experience, but whether our non-inferentially justified moral beliefs can be a posteriori.) In short, the a posteriori nature of some moral beliefs can be seen in the phenomenology of moral-emotional shifts that are brought about by empathic moral dialogue.

\subsection{Empathic Engagement}

What exactly does inclusive and cooperative moral dialogue involve? There is no simple answer to this question, for different situations call for different sorts of dialogue. But there are some general things one can expect in a well-conducted moral dialogue. Generally speaking, cooperative moral dialogue involves communicating social experiences to one another in order to help others more clearly see what it is like to be us. It involves comparing different ways of living in order to identify similarities and differences between the norms that regulate our conduct. Ideally, then, it involves (in some sense) experiencing things from other points of view. I don't mean by this that the moral standpoints of any two persons are interchangeable, such that one can literally occupy another's perspective. Some have held that a procedure like this is key to moral thought (see e.g. Hare 1981), but I am sympathetic to the view that an account of moral reasoning goes wrong if it artificially smooths out our important differences in order to render such standpoint-swapping possible (cf. Jaggar 2001). 
For a more promising way to flesh out our engagement with and experience of other points of view, it will be helpful to consider the nature of empathy. On one influential approach, empathy requires that the empathiser achieve a first-person simulation of their target's experience (see e.g. Goldman 2006 and de Vignemont and Jacob 2012). This conception of empathy can be developed in different (and more-or-less subtle) ways, but it is not the approach I have in mind. For although simulation is one form of empathic engagement, there are also non-simulatory ways of empathising with others. Consider, for instance, that it may be impossible for someone who has never endured profound grief to simulate such an experience in themselves, however hard they try. Moreover, as Ratcliffe (2017) suggests, the particular and personal nature of another person's grief may make it impossible for me to simulate anything like their experience, even if I have my own experience of grief to draw on. Yet something worth calling 'empathy' is possible here, even if it isn't a form of simulation.

Ratcliffe suggests that, surprisingly, the starting point for empathy is 'openness to potential phenomenological differences between self and other' (2017: 205). This is because we ordinarily presuppose a lot of phenomenological commonality when engaging with others. Even if we notice variations between what we want and believe, these are framed by assumptions about shared ways of experiencing and cognising the world. Ratcliffe's point is that empathy can involve suspending such assumptions, in order to investigate the extent to which they really are shared. For instance, we may suspend assumptions concerning our 'social and cultural norms; the emotional import of various states of affairs; the cognitive and practical abilities one brings to bear on a situation', etc. (Ratcliffe 2017: 206). On this approach, empathy is a way of fostering openness to and appreciative understanding of another's experiences. It is therefore not (necessarily) a synchronic moment of simulation. It is a diachronic process of engaging openly with others. And whilst one can empathise with those who aren't present, empathy is ideally a 'prolonged, exploratory, collaborative activity' (Ratcliffe 2017: 214). 
To illustrate, one non-simulatory empathic process involves A's coming to recognise how a particular experience, like grief, fits into B's narrative conception of his life (cf. Goldie 2000 and Gallagher 2012). Without experiencing anything quite like B's grief in herself, there is a meaningful way in which A can come to see things from B's point of view. By learning about what B's life was like before his bereavement, and how it differs after the bereavement, A may come to appreciate B's situation from his perspective. Such learning reveals something of how B experiences and lives in the world. Furthermore, we can (and often must) engage in actual dialogue with others in order to learn about their experiences and life-narratives (cf. Ratcliffe 2017: 202). This is one aspect of the open exploratory process that encourages an empathic appreciation of another person's social world.

In moral cases, the idea is that empathic exploration is key to the cooperative dialogue that we conduct the frontiers of moral inquiry. By experiencing things from other points of view, one can refine one's recognitional range, sense of rejectability, and discriminative acuity for neglected principles like CARE. However, empathic dialogue doesn't just enable a priori understanding of such principles. In the next section I will argue that, by examining the role of empathy in moral dialogue, we find a compelling case for the claim that some moral beliefs are non-inferentially and a posteriori justified.

\subsection{Shifting Moral Emotion}

On the view that I sketch in this section, it is certain emotional experiences that justify moral belief, and their justificatory role can be seen by examining the empathic dialogical process. Emotions are playing an increasingly important role in views of moral knowledge, including in intuitionist views (see e.g. Audi 2013). My discussion is distinctive in that I defend an epistemic role for emotion by explaining what happens when one undergoes a shift in one's moral-emotional framework - that is, my case for a posteriori moral intuition appeals to the phenomenology of such moral-emotional shifts. 
I use the term 'moral-emotional framework' to refer to the cluster of moral emotions (guilt, blame, resentment, admiration, disgust, etc.) through which one filters non-moral but (potentially) morally relevant data. Consider, for instance, the non-moral fact that $\Phi$-ing will cause pain to an innocent person. And suppose that awareness of this leads A to feel aversion toward $\Phi$-ing, B to feel drawn toward $\Phi$-ing, whilst $C$ feels nothing either way. A, B, and C differ in moral-emotional framework. Of course, each of them could ignore or override their feelings and still form the belief that $\Phi$-ing is wrong. (B may also have a second-order desire to not be drawn toward $\Phi$-ing - this will be part of his moral-emotional framework as well). But the thought is that the moral-emotional framework filters the vast array of non-moral information that we receive from the environment - this framework makes some non-moral facts appear morally salient, and other such facts appear irrelevant. A moral-emotional framework can be more-or-less refined, and reflection may reveal a need to work at improving it. What matters that, by considering how a moral-emotional framework changes through empathic dialogue, we reveal that some emotional experiences play a justificatory role.

Consider that cooperative dialogue, as I described it, is not an emotionally neutral activity. Empathic engagement may not require that we simulate the emotions of others, but it does involve suspending assumptions about the emotional import of various states of affairs. We do this not to set emotional factors aside, but to open our minds to how others experience the emotional import of those states of affairs. This enables us to appreciatively understand whether and why they have feelings that we do not. In moral cases, it may mean reaching an empathic appreciation of why you admire things to which I am indifferent, or why I feel an aversion to things that you admire. As a result, empathic dialogue often contributes to an affective shift - for instance, it can shake you out of indifference to a certain type of situation by amending the moral-emotional framework through which you view such situations. The ways in which moral-emotional frameworks get amended will be complex, but by explaining how this process works we will discover an epistemic role for moral emotion. 
Changes in a moral-emotional framework involve both cognition and affect. Learning new information leads you to adjust some of your beliefs, and your empathic appreciation of another's experience may alter your emotional reaction to their conduct (and, thus, to similar conduct). For instance, you may feel less resentful toward a wrongdoer if you empathically appreciate your shared human frailties. An instructive parallel here is the affective shift that results from effective cognitive therapy. Cognitive therapy works (when it works) by helping patients to adjust beliefs or goals. For instance, Thagard (2000: 207) describes a depressed patient who, convinced that she was a failure as a mother, felt that she should kill herself. A therapist worked with this patient to identify times when she had acted as good mothers act, thus building evidence against a negative belief. Thagard argues that, by revising this and other such beliefs, the patient could 'change her overall emotional appraisal of herself and her situation, which could lead to a dramatic improvement in her mood' (2000: 210).

Thagard's gloss on this involves the patient shifting from her coherent but negative system of appraisal to a coherent and positive system of appraisal. It is thus a process involving inference. Revising one belief/goal leads the patient to revise other beliefs/goals, for she (perhaps implicitly) infers that they are wrong. This inferential process leads to an affective reappraisal of her situation. However, whilst the process by which this reappraisal is achieved is inferential, the resulting mood change is most plausibly seen as reframing her non-inferential, direct experiences of the world. For instance, before therapy the depressed patient experienced her child as a thing to which she could not connect. This experience was not inferred from her negative system of appraisal - that seems an overly intellectualised view of her experience. She instead had an immediate feeling of alienation from a person to which she knew she should feel deeply connected. After therapy she experienced her child differently. The feeling of connection returned - her improved mood reframed how she experienced herself and her situation. The process that led to this affective reframing did involve inference and reasoning, but the experience of connectedness that it enabled was not inferred from anything. 
What I'm suggesting is that, when we consider the phenomenology of shifts in affect, we find that there are cases in which an inferential process enables the shift, and the shift enables new immediate experiences of one's situation. In particular, when the depressed patient's shift in mood enables her to feel connected to her child, she doesn't (implicitly or explicitly) infer this from her new positive system of appraisal. Instead, the feeling of connectedness is made possible by a new (or repaired) way of engaging with the world, and this new way of engaging with the world is the result of her emotional reappraisal. That is, an emotional reappraisal creates or reintroduces a range of experiential possibilities for her by psychologically reorienting her in relation to reality. Reality presents itself to her in a new (and improved) way, for the lens through which she now views it is positive.

My claim is that, just as a therapeutic dialogue can lead to a depressed patient undergoing an affective shift, empathic dialogue can lead to shifts in an inquirer's moral-emotional framework. Both types of dialogue involve a certain amount inferential work (the systematic revision of beliefs and goals, for example), and both types of dialogue can lead to an emotional reorientation. In the moral cases, this is achieved via empathic appreciation of how other people experience the world, but it consists in an amendment to the moral-emotional framework through which your personal experiences of a moral situation are framed - this is a personal reorientation that renders different moral-emotional experiences possible or morally salient for you. Thus, on the view I'm proposing it needn't be empathy itself that serves as a justifier for moral belief. Rather, empathy enables one's moral-emotional framework to change (and improve) such that one's moral-emotional experiences (guilt, blame, resentment, admiration, disgust, etc.) come to track moral facts (and morally relevant non-moral facts) to which one had previously been insensitive or insufficiently sensitive. And these experiences, I'll argue, provide non-inferential and a posteriori justification for at least some moral beliefs. In short, by exploring the phenomenology of shifts in a moral-emotional framework, we see the general role that moral emotions play in the acquisition of non-inferentially justified moral beliefs. 
Consider first an aesthetic case, adapted from Ratcliffe (2017: 211). Suppose that you and a friend are examining a painting. You feel indifferent to it, and form the belief that it is a mediocre work. That is, your aesthetic experience of indifference is the basis for your aesthetic judgement about the artwork's quality. But suppose that your friend starts to tell you how they feel about the painting. It reminds them of their experience with depression, an experience that you haven't had. You continue to examine the painting as your friend describes their depression, and your feelings towards it change. That is, by empathising with your friend, your experience of the art is enriched. You become absorbed by it, and you shift from feeling indifferent to feeling moved by its faithful depiction of what your friend is describing. You thus come to believe that it is a great work of art. What happens here is that you acquire a new aesthetic belief, but not through any inference from your other beliefs. For instance, you don't need to infer your aesthetic belief from the beliefs about depression (etc.) that you have attained via a friend's testimony. Nor is this plausibly seen as a case of your coming to adequately understand some aesthetic principle that can be applied to the work. Instead, changes in your personal aesthetic experience lead you to a new aesthetic belief. Empathic dialogue reorients your engagement with the work, making a new aesthetic experience possible for you.

My claim is that something similar happens in the moral case. Here's a crude example to illustrate the point. Suppose that you and a friend witness a man repeatedly kicking a dog. You are unmoved, for you have no experience of dogs, and simply see them as mindless beasts. You feel indifferent toward the situation, believing that the treatment of the dog is morally neutral. Your friend, however, does have experience with dogs. He talks to you about the dogs he has known over the years, conveying a sense of how such treatment can cause not only short-term pain but long-term trauma to a dog. As you listen and empathically engage with what your friend says, your experience of what you are witnessing is altered - you notice the dog's helplessness, and you start to feel disgust at its mistreatment. This leads you to believe that what is being done to the dog is wrong. 
What happens here is that your moral belief changes, but not through inference from other moral and non-moral beliefs. For instance, you don't need to infer your new moral belief from the beliefs about dogs that you have attained via your friend's testimony. Nor is this plausibly seen as a case of your coming to adequately understand certain moral principles regarding the kicking of dogs. Instead, changes in your own experience of the situation lead you to a different moral belief. Empathic dialogue helps to reorient your engagement with what you're seeing. It reframes the way the situation presents itself to you, and shifts your moral-emotional reaction. This reorientation is achieved through an inferential process - what your friend says to you leads you to revise certain of your background beliefs in ways that lead to a moral-emotional reappraisal. But the experiences made possible by this reappraisal are immediate - they are not inferred from anything. And these experiences directly justify your new moral belief about the situation, for they are non-inferential ways of tracking moral or morally relevant facts to which you were once insensitive or insufficiently sensitive.

The case of your friend casually describing his experience with dogs whilst you both watch a dog being kicked is, of course, contrived. But it illustrates the process by which empathic dialogue can shift a moral-emotional framework, and thereby furnish one with a new emotional orientation toward a situation or type of situation. This reorientation yields new moral experiences, and some moral beliefs are based directly on these experiences. In short, by thinking about the way in which empathic dialogue can shift a moral-emotional framework, we get an intuitionist-friendly case for the claim that some of our moral beliefs are non-inferentially and a posteriori justified. I don't mean to suggest that the epistemic role of moral emotions lies solely in our undergoing moral-emotional shifts. Rather, my claim is that the phenomenology of dialogically-induced moral-emotional shifts is instructive because the non-inferential justificatory role of our moral emotions is writ large here: such shifts lead us to form justified moral beliefs directly, not through inference or propositional understanding. 


\section{Conclusion}

The social nature of moral inquiry is something that most intuitionists neglect. No intuitionist has said that moral inquiry must be individualistic, but few ask what we can learn by considering the importance of inclusive and cooperative moral dialogue. I've argued that we learn something about the nature of non-inferential moral knowledge. Explaining how moral dialogue works points us to a view on which non-inferentially justified moral beliefs come in both an apriori and an a posteriori variety. Thus, whilst any moral epistemology must capture the need for inclusive and cooperative dialogue, intuitionists have special reason to pay close attention to the collaborative nature of moral inquiry.

Dr Stephen Ingram

University of Manchester, UK

\section{Acknowledgements}

I am grateful to David Liggins, Jimmy Lenman, and Graham Bex-Priestley for their comments on earlier versions of this paper. I am also grateful to the two anonymous referees for this journal for their very useful suggestions. I would also like to thank Lizzy Kirkham, Denise Fox, Shirley Carter, and Sonja Sen. 


\section{References}

Anderson, E. (1995) 'Feminist Epistemology: An Interpretation and Defense', Hypatia 10, 50-84.

Antony, L. (1993) 'Quine as Feminist: The Radical Import of Naturalized Epistemology', in L.

Antony and C. Witt (eds.), A Mind of One's Own, 185-226. Boulder: Westview Press.

Audi, R (2004) The Good in the Right: A Theory of Intuition and Intrinsic Value. Princeton, NJ:

Princeton University Press.

------ (2013) Moral Perception. Princeton, NJ: Princeton University Press.

------ (2019) 'Understanding, Self-Evidence, and Justification', Philosophy and Phenomenological Research 99, 358-381.

Bengson, J, T. Cuneo, and R. Shafer-Landau. (Forth) 'Trusting Moral Intuitions', Nous. [https://onlinelibrary.wiley.com/doi/pdf/10.1111/nous.12291]

Bubeck, D. (1995) Care, Gender, and Justice. Oxford: Oxford University Press.

Burge, T. (1993) 'Content Preservation', Philosophical Review 102, 457-488.

Cowan, R. (2016) 'Epistemic Perceptualism and Neo-Sentimentalist Objections.' Canadian Journal of Philosophy 46, 59-81.

de Vignemont, F. and P. Jacob. (2012) 'What is it like to feel another's pain?', Philosophy of Science 79, 295-316.

Gallagher, S. (2012) 'Empathy, Simulation and Narrative', Science in Context 25, 355-381.

Gilligan, C. (1982) In a Different Voice: Psychological Theory and Women's Development. Cambridge, MA: Harvard University Press.

Goldie, P. (2000) The Emotions: A Philosophical Exploration. Oxford: Oxford University Press.

Goldman, A.I. (2006) Simulating Minds: The Philosophy, Psychology, and Neuroscience of Mindreading. Oxford: Oxford University Press.

Harding, S. (1991) Whose science? Whose knowledge?, Ithaca, N.Y.: Cornell University Press. (1993) 'Rethinking Standpoint Epistemology: 'What is Strong Objectivity?”, in L. Alcoff and E. Potter (eds.), Feminist Epistemologies, 49-82. New York: Routledge. 
Hare, R.M. (1981) Moral Thinking: Its Levels, Method, and Point. Oxford: Oxford University Press.

Held, V. (2006) The Ethics of Care: Personal, Political Global. Oxford: Oxford University Press.

Huemer, M. (2005) Ethical Intuitionism. New York: Palgrave MacMillan.

Jaggar, A. (2000) 'Ethics Naturalized: Feminism’s Contribution to Moral Epistemology', Metaphilosophy 31, 452-468.

(2001) 'Feminist Ethics', in L. Becker and C. Becker (eds.), Encyclopedia of Ethics: Volume I, $2^{\text {nd }}$ edn, 528-539. New York: Routledge.

Jaggar, A and T. Tobin. (2013) 'Naturalizing Moral Justification: Rethinking the Method of Moral Epistemology', Metaphilosophy 44, 409-439.

Kaspar, D. (2012) Intuitionism. London: Bloomsbury.

Keller, E.F. 1985. Reflections on Gender and Science. New Haven: Yale University Press.

Kirchin, S. (2005) ;What is Intuitionism and Why be an Intuitionist?', Social Theory and Practice 31, $581-606$.

Kittay, E.F. (1999) Love's Labour: Essays on Women, Equality, and Dependency. New York: Routledge. Longino, H. (1990) Science as Social Knowledge: Values and Objectivity in Scientific Inquiry. Princeton, NJ: Princeton University Press.

McDowell, J. (1998) 'Aesthetic Value, Objectivity, and the Value of the World', in Mind, Value, and Reality, 112-130. Cambridge, MA: Harvard University Press.

Nagel, T. (1986) The View from Nowhere. Oxford: Oxford University Press.

Noddings, N. (2002) Starting at Home: Caring and Social Policy. London: University of California Press.

O'Connor, P. (2008) Morality and Our Complicated Form of Life: Feminist Wittgensteinian Metaethics. University Park, Pennsylvania: Pennsylvania State University Press.

Oddie, G. (2005) Value, Reality, and Desire. Oxford: Oxford University Press.

McBrayer, J. (2010) 'A Limited Defense of Moral Perception', Philosophical Studies 149, 305-320.

Moore, G.E. (1903) Principia Ethica. Cambridge: Cambridge University Press. 
Ratcliffe, M. (2015) Experiences of Depression: A Study in Phenomenology. Oxford: Oxford University Press.

----- (2017). 'Empathy Without Simulation', in T. Fuchs, M. Summa, and L. Vanzago (eds.), Imagination and Social Perspectives: Approaches from Phenomenology and Psychopathology, 199-220. London: Routledge.

Ross, W.D. (1930/2002) The Right and the Good. Oxford: Oxford University Press.

Ruddick, S. (1989) Maternal Thinking: Toward a Politics of Peace. Boston, MA: Beacon Press.

Shafer-Landau, R. (2003) Moral Realism: A Defence. Oxford: Oxford University Press.

Sidgwick, H. (1907) The Methods of Ethics, $7^{\text {th }}$ edn. London: Hackett.

Solomon, M. (2001) Social Empiricism. Cambridge, MA: MIT Press.

Stratton-Lake, P. (2016.) 'Intuition, Self-Evidence, and Understanding', in R. Shafer-Landau (ed.) Oxford Studies in Metaethics 11, 28-44. Oxford: Oxford University Press.

Thagard, P. (2000) Coherence in Thought and Action. London: MIT Press.

Tropman, E. (2009) 'Renewing Moral Intuitionism', Journal of Moral Philosophy 6, 440-463.

Tronto, J. and B. Fisher. 1990. 'Toward a Feminist Theory of Caring', in E. Abel and M. Nelson (eds.) Circles of Care, 36-54. New York: SUNY Press.

Walker, M. U. (2007) Moral Understandings: A Feminist Study in Ethics, $2^{\text {nd }}$ edn. Oxford: Oxford University Press.

Wiggins, D. (1987) 'Truth, Invention, and the Meaning of Life,' in Needs, Values, Truth, 87-139. Oxford: Blackwell.

Wiland, E. (2017) 'Moral Testimony: Going on the Offensive', in R. Shafer-Landau (ed.) Oxford Studies in Metaethics 12, 51-75. Oxford: Oxford University Press.

Williams, B. (1978) Descartes: The Project of Pure Enquiry. London: Penguin. 